\title{
Acute toxicity formation potential of benzophenone-type UV filters in chlorination disinfection process
}

\author{
Qi Liu ${ }^{1,2}$, Zhenbin Chen ${ }^{1,3, *}$, Dongbin Wei ${ }^{2, *}$, Yuguo $\mathrm{Du}^{2}$ \\ 1. School of Material Science and Engineering, Lanzhou University of Technology, Lanzhou 730050, China. E-mail: lsalq1986@163.com \\ 2. State Key Laboratory of Environmental Chemistry and Ecotoxicology, Research Center for Eco-Environmental Sciences, \\ Chinese Academy of Sciences, Beijing 100085, China \\ 3. State Key Laboratory of Gansu Advanced Non-ferrous Metal Materials, Lanzhou University of Technology, Lanzhou 730050, China
}

\section{A R T I C L E I N F O}

\section{Article history:}

Received 19 March 2013

revised 27 April 2013

accepted 09 May 2013

\section{Keywords:}

acute toxicity formation potential

benzophenones

UV filters

chlorination

photobacterium assay

DOI: 10.1016/S1001-0742(13)60411-8

\begin{abstract}
A B S T R A C T
Benzophenones (BPs) are a class of widely used UV filters, which have been frequently detected within multiple environmental matrices. Disinfection is a necessary process in water treatment processes. The transformation behaviors and toxicity changes of 14 BP-type UV filters during chlorination disinfection treatment were investigated in this study. A new index, the acute toxicity formation potential, was proposed to evaluate the toxicity changes and potential risks of BP-type UV filters during chlorination treatment. It was found that 13 of 14 BP-type UV filters exhibited toxicity decreases in the chlorination disinfection process, more or less, while one showed a toxicity increase. The toxicity changes were dependent on substitution effects, such that 2,4-di-hydroxylated or 3-hydroxylated BPs exhibited significant toxicity decreases after chlorination treatment due to the ready cleavage of the aromatic ring. Importantly, the acute toxicity changes could be duplicated in an ambient water matrix.
\end{abstract}

\section{Introduction}

With the increasing warming of the global climate, depletion of the ozone layer is becoming much more serious. As a result, more and more ultraviolet ray (wavelength at 290$400 \mathrm{~nm}$ ) exposure can occur to the human body, which can cause erythema, ambustion, skin darkening and aging or even skin cancer. Consequently, UV-filters are widely used to protect people from ultraviolet ray irradiation.

Benzophenone compounds (BPs) are able to absorb ultraviolet light UVA (320-400 nm) and UVB (290-320 $\mathrm{nm}$ ) preferentially, and are widely used as UV filters in effectively preventing some common skin diseases and even skin cancer (Moloney et al., 2002). BP-type UV filters

\footnotetext{
*Corresponding author. E-mail: zhenbinchen@163.com (Zhenbin Chen), weidb@rcees.ac.cn (Dongbin Wei)
}

are widely employed in the manufacture of cosmetics and other personal care products. They can also be used as agricultural chemicals, flavor ingredients and UV stabilizers in plastic surface coatings for food packaging to prevent photo-degradation of the polymer packaging or the food itself (Suzuki et al., 2005; Zenker et al., 2008). The maximum authorized concentration of benzophenone- 3 in sunscreens is $10 \%$ in EU, that of 2,2'-dihydroxy-4methoxybenzophenone is $3 \%$ in Korea (EEC, 1983; Jeon et al., 2006), and benzophenone-4 is permitted for use in cosmetics at a maximum concentration of $10 \%$ in Japan (MHLW, 2000). Hence, a large amount of BP remnants and their metabolites have entered into the aqueous environment directly or indirectly via wash off from skin and clothes during water recreational activities or discharge of sewage and swimming pool waters. The concentration of benzophenone-4 ranged from 237 to $1481 \mathrm{ng} / \mathrm{L}$ in wastewater samples from Galicia (NW Spain) (Rodil et al., 2008). 
The mean concentration of 2,4-dihydroxybenzophenone in 25 rivers was $47 \mathrm{ng} / \mathrm{L}$ in Korea, and benzhydrol, a major metabolite of benzophenone, was detected with a highest concentration of $204 \mathrm{ng} / \mathrm{L}$ (Jeon et al., 2006). BP-type UV filters have the potential for bioaccumulation due to their lipophilic characteristics. Analyses of human milk provided evidence for the UV filters' possible bioaccumulation, and residuals of benzophenone- 3 were detected in human breast milk samples at levels up to $445 \mathrm{ng} / \mathrm{g}$ lipid (Hany and Nagel, 1995). In human urine, benzophenone3 and its metabolite benzophenone-1 were detected after application of commercially available sunscreen products to the skin (Felix et al., 1998).

BP-type UV filters exhibited both estrogenic and antiandrogenic properties in various organisms in some bioassay studies; for example, exerting a uterotrophic effect in vivo, stimulating cell proliferation of MCF-7 breast cancer cells, and elevating the secretion of tumor marker pS2 in vitro (Zenker et al., 2008; Balmer et al., 2005; Schlumpf et al., 2001; Ma et al., 2003; Schreurs et al., 2005). Moreover, BP-type UV filters have potential genotoxic effects. It was reported that benzophenone was negative in a Salmonella mutagenesis assay (Mortelmans et al., 1986) and in the E. coli pol $A$ assay (Fluck et al., 1976), while 2-hydroxy-4-methoxy benzophenone (HMB) and 2,2'-dihydroxy-4-methoxy benzophenone (DHMB) were positive in a Salmonella mutagenesis assay (Zeiger et al., 1987; French, 1992), and DHMB and 2,3,4-trihydroxy benzophenone (THB) had genotoxic effects in L5178Y cells (Jeon et al., 2007). Up to now, the systematic research on toxicity of BP-type UV filters has been quite insufficient.

Chlorination disinfection, due to its strong oxidation ability, low cost, and effective persistence, is still one of the most widely used techniques in water treatment practices. However, free available chlorine (FAC), in addition to killing harmful pathogens, may also react with some chemical pollutants remaining in water, and possibly create poisonous and harmful disinfection byproducts (DBPs). It was reported that, among all the water treatment techniques, chlorine disinfection produced more DBPs than other disinfectants (Pan et al., 2010). There is little research on the transformation characteristics and potential health risk of BP-type UV filters in the chlorination disinfection process.

Therefore, 14 BP-type UV filters were selected in this study to investigate their transformation behaviors in the chlorination disinfection process. The acute toxicity of each compound before and after chlorination treatment was measured using a photobacterium bioassay. In addition, the transformation ratio of each BP-type UV filter was detected with the help of gas chromatography-mass spectrometry or liquid chromatography-mass spectrometry. The transformation behaviors and toxicity changes of BPtype UV filters during the chlorination disinfection process were clarified on the basis of their molecular structures. This study could provide scientific data for evaluating the environmental fate and potential risk of BP-type UV filters, and give a theoretical reference for optimizing operating parameters in chlorination disinfection practices.

\section{Materials and methods}

\subsection{Reagents and instruments}

Fourteen benzophenone compounds ( $>97.5 \%$ purity) listed in Table 1 were purchased from Sigma-Aldrich (USA). All of these reagents were used for chlorination treatment and toxicity tests directly without further purification. Salts including $\mathrm{Na}_{2} \mathrm{HPO}_{4} \cdot 12 \mathrm{H}_{2} \mathrm{O}$ and $\mathrm{NaH}_{2} \mathrm{PO}_{4} \cdot 2 \mathrm{H}_{2} \mathrm{O}$ for preparing phosphate buffer ( $\mathrm{pH} 7.5,0.2 \mathrm{~mol} / \mathrm{L}), \mathrm{KH}_{2} \mathrm{PO}_{4}$, $\mathrm{NaCl}$ and $\mathrm{Na}_{2} \mathrm{SO}_{3}$ for the bioassay medium and quenching solutions, were purchased from Sigma-Aldrich (USA). Yeast extract, tryptone and glycerol were obtained from BD (USA). Methanol and acetone (HPLC grade) were purchased from Fisher (USA). Dimethylsulfoxide (DMSO) was obtained from Amresco (USA). $\mathrm{NaClO}(8 \%)$ aqueous solution was obtained from Wako (Japan). Ultrapure water used in the experiments was produced from a Millipore ultrapure water system. Liquid chromatography-quadrupole time of flight-mass spectrometry (micrOTOF QII, Bruker, Germany) was used to quantify the transformation ratios of $14 \mathrm{BPs}$ in the chlorination disinfection process. According to the low polarities of BP1, BP2 and BP12, gas chromatography-mass spectrometry (7890A/5975C, Agilent, USA) was used to quantify their transformation ratios.

\subsection{Chlorination treatment and sample preparation}

In order to obtain reliable toxicity data, the initial concentration of studied BPs was set as $2 \mathrm{mmol} / \mathrm{L}$. Meanwhile, considering the experimental conditions for measuring disinfection byproducts formation potential (DBPsFP) recommended by APHA (1998), in this study, each BP solution was prepared in $25 \mathrm{~mL}$ of phosphate buffer (pH 7.5, $20 \mathrm{mmol} / \mathrm{L})$ containing $1 \%(\mathrm{~V} / \mathrm{V})$ of methanol, and treated with 10 equivalents of free available chlorine $(\mathrm{FAC}=20 \mathrm{mmol} / \mathrm{L}, \mathrm{BP}=2 \mathrm{mmol} / \mathrm{L},[\mathrm{FAC}] /[\mathrm{BP}]=10)$. After $24 \mathrm{hr}$, sodium sulfite solution (1.2 equivalents to $\mathrm{FAC}$ ) was added to quench residual FAC. A control solution without adding FAC was set as well. The two solutions with and without FAC treatment were respectively freezedried, re-dissolved in $10 \mathrm{~mL}$ of mixed organic solvents (50\% methanol and 50\% acetone) for desalination, and filtered through a $0.22-\mu \mathrm{m}$ nylon membrane. The filtrate was brought to $10 \mathrm{~mL}$ volume again with mixed organic solvents. A 4-mL aliquot was analyzed by GC-MS and LC-MS, and the remaining $6 \mathrm{~mL}$ aliquot was blow-dried with a gentle $\mathrm{N}_{2}$ flow and re-dissolved in $1 \mathrm{~mL}$ DMSO 


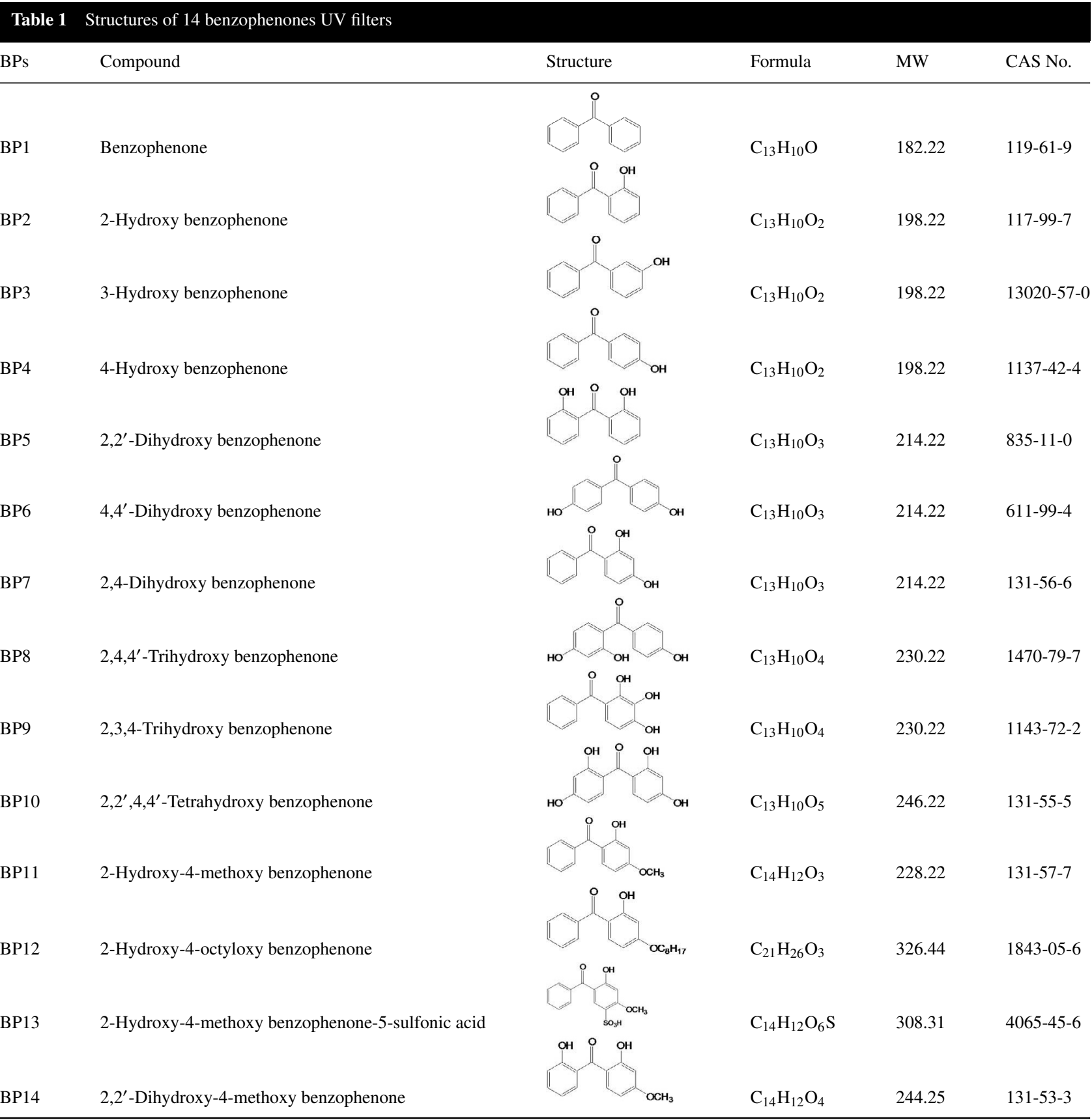

solvent as stock solution for toxicity testing. In order to avoid the possible negative effects of DMSO on the toxicity test, each stock solution was diluted with $3 \% \mathrm{NaCl}$ solution to reduce the concentration of DMSO to $1 \%$ in the exposure solution. It has been demonstrated that $1 \%$ DMSO has no significant influence on photobacterium bioassays (Nałecz-Jawecki et al., 1997). The chlorination treatment for each BP-type UV filter was conducted in triplicate.

\subsection{Toxicity test}

The photobacterium bioassay method quantifies the decrease in light emission from the Photobacterium phosphoreum bacteria as a result of exposure. The bacteria $P$. phosphoreum T3 Straus was provided as freeze-dried powder by the Institute of Soil Science, Chinese Academy Sciences, Nanjing, China. In order to obtain a doseresponse curve for each sample, six different concentration gradients in four parallels were set in the toxicity tests. 
The stock solution was added into a 96-well microplate and diluted with $3 \% \mathrm{NaCl}$ solution to $180 \mu \mathrm{L}$ in each well to limit the exposure level of DMSO to $1 \%$. In each test, $3 \% \mathrm{NaCl}$ solution, $1 \%$ DMSO solution and $\mathrm{HgCl}_{2}$, were respectively set as negative control, solvent control and positive control. After 30 min of pre-culturing in $3 \% \mathrm{NaCl}$ solution, $20 \mu \mathrm{L}$ P. Phosphoreum suspension was added into each well. The microplate was shaken and exposed for $15 \mathrm{~min}$ at $(20 \pm 1)^{\circ} \mathrm{C}$, and the bioluminescence intensity was measured by Synergy ${ }^{\mathrm{TM}} 2$ Multi-Mode Microplate Reader (Biotek, USA). Toxicity was expressed as the luminescence intensity inhibition ratio (IR, \%):

$\mathrm{IR}=\frac{L_{\mathrm{NC}}-L_{\mathrm{sample}}}{L_{\mathrm{NC}}} \times 100 \%$

where, $L$ represents luminescence intensity and NC represents negative control. The median effect concentration EC50 was calculated from the dose-response curve of each sample when the IR was 50\% (Ye et al., 2011). It was proved that the controlled trials of buffer salts had no effect on the toxicity of the photobacterium bioassay in our study.

In addition, in order to conveniently evaluate the acute toxicity variation before and after chlorination treatment, an acute toxicity formation potential (ATFP) index was proposed as:

$\mathrm{ATFP}=\mathrm{TE}_{\text {pre-disinf }} / \mathrm{TE}_{\text {post-disinf }}$

$\mathrm{TE}=\mathrm{EC}^{50_{\text {sample }}} / \mathrm{EC} 50_{\text {ref }}$

where, $\mathrm{TE}_{\text {pre-disinf }}$ and $\mathrm{TE}_{\text {post-disinf }}$ are the toxicity equivalent before and after chlorination disinfection treatment, respectively. $\mathrm{EC} 50_{\text {sample }}$ and $\mathrm{EC} 50_{\text {ref }}$ are median effect concentrations of the sample and positive reference substance $\left(\mathrm{HgCl}_{2}\right)$, respectively. ATFP $>1$ means acute toxicity increase after chlorination treatment, ATFP $<1$ means acute toxicity decrease after chlorination treatment (Table 2). The higher the ATFP value is, the greater the increase of acute toxicity will be after chlorination treatment.

\subsection{Quantification method}

An ultra performance liquid chromatography (Ultimate 3000, Dionex, USA) system with Agilent SB-C18 column

Table 2 Acute toxicity formation potential (ATFP) of BP-type UV filters in chlorination treatment

\begin{tabular}{llll} 
BPs & ATFP & BPs & ATFP \\
\hline BP1 & 0.9997 & BP8 & 0.2189 \\
BP2 & 0.9617 & BP9 & 0.0429 \\
BP3 & 0.2686 & BP10 & 0.1596 \\
BP4 & 0.9000 & BP11 & 0.3978 \\
BP5 & 0.4206 & BP12 & 1.0946 \\
BP6 & 0.4152 & BP13 & 1.5947 \\
BP7 & 0.0661 & BP14 & 0.3469 \\
\hline
\end{tabular}

$(4.6 \times 150 \mathrm{~mm}, 5 \mu \mathrm{m})$, coupled with a quadrupoletime of flight mass spectrometer (micrOTOF QII, Bruker, Germany) was used to quantify the transformation ratios of BPs, Injection volume was $1 \mu \mathrm{L}$ and flow rate was $0.4 \mathrm{~mL} / \mathrm{min}$, isocratic elution was carried out with $40 \%$ aqueous solution containing $0.1 \%(\mathrm{~V} / \mathrm{V})$ of formic acid and $60 \%$ methanol. 11 BPs (all except BP1, BP2 and BP12) had acceptable responses. The MS analyses were conducted using negative mode electrospray ionization $\left(\mathrm{ESI}^{-}\right)$over a mass scan range of $50-1000 \mathrm{~m} / \mathrm{z}$. The temperature of the spray chamber and dry gas flow rate were set at $250^{\circ} \mathrm{C}$ and $6 \mathrm{~L} / \mathrm{min}$, respectively.

An Agilent 7890A/5975C gas chromatography/mass spectrometry (GC-MS) system was used to quantify the transformation ratios of $\mathrm{BP} 1, \mathrm{BP} 2$ and $\mathrm{BP} 12$ during chlorination. A capillary GC column that was $30 \mathrm{~m}$ in length and $250 \mu \mathrm{m}$ in internal diameter with a $0.25 \mu \mathrm{m}$ film thickness of stationary phase of $5 \%$ phenyl methyl siloxane was used. The flow rate of helium, which was used as a carrier gas, was $1.0 \mathrm{~mL} / \mathrm{min}$. The injector temperature was set to $280^{\circ} \mathrm{C}$ and samples were injected $(1 \mu \mathrm{L})$ in the splitless mode. The GC column temperature was programmed from $70^{\circ} \mathrm{C}$, ramped at $10^{\circ} \mathrm{C} / \mathrm{min}$ to $200^{\circ} \mathrm{C}$, and held for $2 \mathrm{~min}$, then ramped at $20^{\circ} \mathrm{C} / \mathrm{min}$ to $300^{\circ} \mathrm{C}$ and held for $5 \mathrm{~min}$. The interface was maintained at $280^{\circ} \mathrm{C}$, and the mass spectra were obtained at $70 \mathrm{eV}$. The samples were analyzed under full-scan mode over a mass range of $50-500 \mathrm{~m} / \mathrm{z}$.

\section{Results and discussion}

Fourteen pairs of EC50 values for the studied BP-type UV filters before and after chlorination treatment are shown in Fig. 1. It can be seen that the EC50 values for BPs before chlorination ranged from 2.35 to $706.54 \mathrm{mg} / \mathrm{L}$,

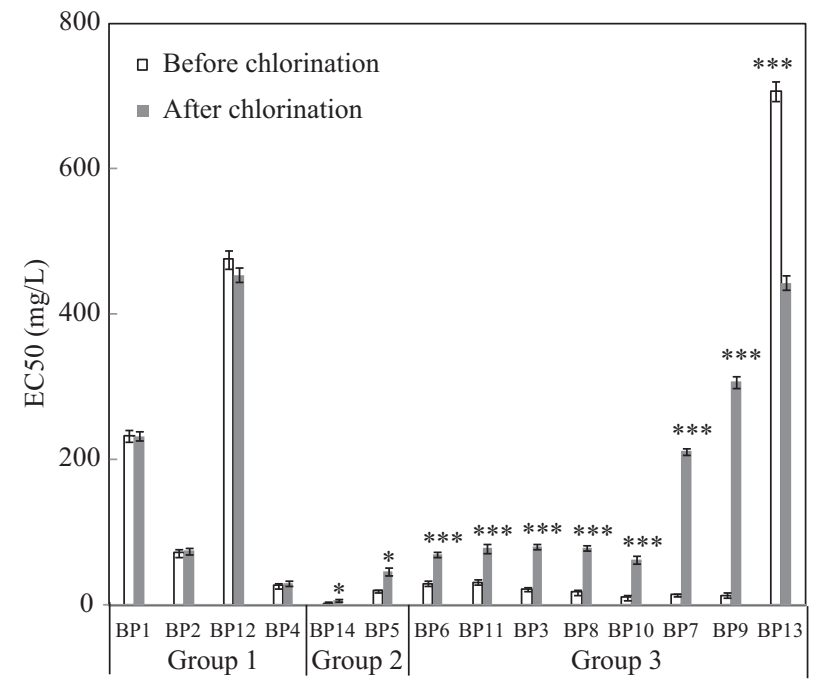

Fig. 1 EC50 values of 14 BP-type UV filters before and after chlorination treatment $\left({ }^{*}\right.$ means $0.01<p<0.05$; ${ }^{* * *}$ means $p<0.001$ ). 
and chlorination treatment changed their toxicity levels obviously. The difference for each pair of EC50 values before and after chlorination treatment was statistically tested with the unpaired-test method (GraphPad Prism 5), and the 14 pairs were divided into three groups (Group 1, Group 2, and Group 3 in Fig. 1). Meanwhile, based on the 14 ATFP values in Table 2, a cluster analysis was conducted as well. The 14 BP-type UV filters were divided into three clusters as shown in Fig. 2. BP1, BP2, BP12, and BP4 were included in Cluster 1, which had no significant toxicity change after chlorination treatment. BP14, BP5, BP6, BP11, BP3, BP8, BP10, BP7 and BP9 were included in Cluster 2, which had significant toxicity decrease after chlorination treatment. BP13 was included in Cluster 3, which had a significant toxicity increase after chlorination treatment. The cluster analysis result was in accordance with that in Fig. 1. In order to better understand the inherent reasons for the toxicity change after chlorination treatment, the molecular structures of the BPs and their transformation ratios were explored. The transformation ratios of the 14 BP-type UV filters in chlorination treatment were determined and shown in Fig. 3. The limits of detection for 14 BPs ranged from 1.35 to $96.87 \mu \mathrm{g} / \mathrm{L}$. It can be seen that, except for BP1, BP12, $\mathrm{BP} 2$ and BP11, which had low transformation ratios $(5 \%$, $3 \%, 28 \%$ and $59 \%$, respectively), the remaining BPs had high transformation ratios (more than $80 \%$ ).

\subsection{Toxicity without significant changes}

As mentioned above, the transformation activity of precursors (BP-type UV filters) is the inherent driver for toxicity changes during chlorination treatment. Therefore, unchanged toxicity in chlorination treatment might be attributed to two possible cases, one being low transformation ratios of precursors, and the other similar toxicity level of products compared with their precursors. As shown in Fig. 3, the four compounds BP1, BP2, BP12 and BP4 in Cluster 1 (shown in Fig. 2) belonged to two cases. BP1 and BP12 had low transformation activity and hardly reacted

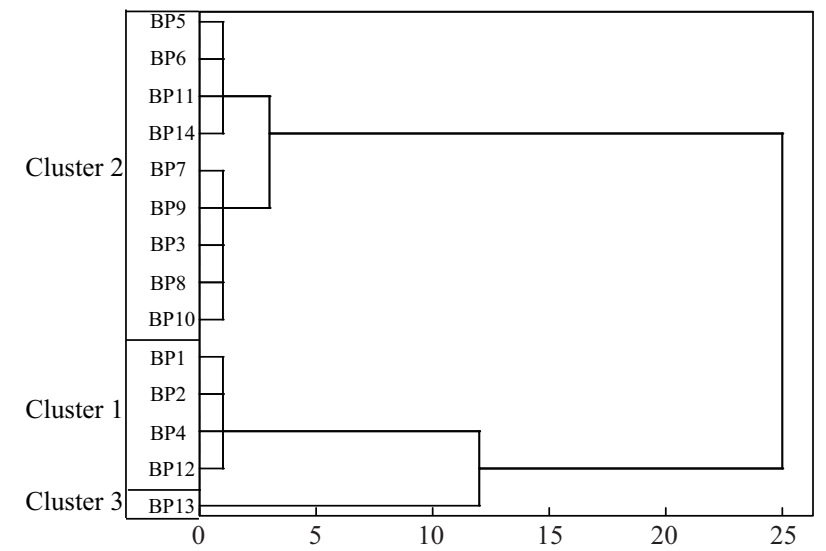

Fig. 2 Cluster analysis on acute toxicity formation potential (ATFP) of 14 BP-type UV filters in chlorination treatment.

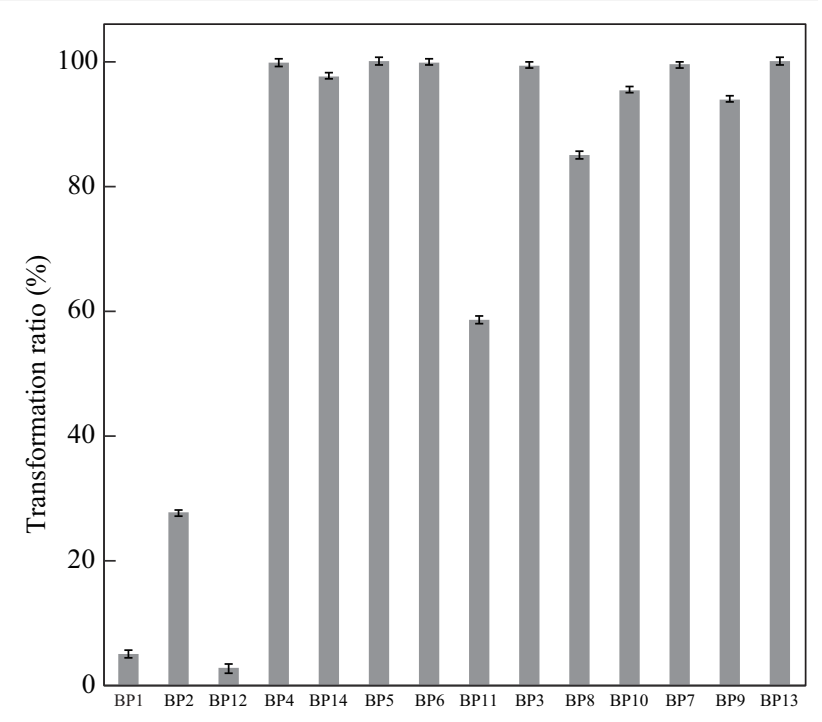

Fig. 3 Transformation ratios of the 14 BP-type UV filters in chlorination treatment.

with FAC (transformation ratios were less than 5\%). BP2 and $\mathrm{BP} 4$ belonged to the second case, either partially (BP2, ca. $30 \%$ transformation ratio) or completely (BP4, 100\% transformation ratio) reacting with FAC, so that the likely reason for unchanged toxicity was that the products had toxicity characters similar to their precursors.

Considering the molecular structures of these four compounds, BP1 has no functional group on the benzophenone skeleton and no active site, thus exhibiting a low transformation ratio. BP2 has one hydroxyl group on the benzene ring. As is known, phenolic hydroxyl not only has an electron-withdrawing inductive effect, but also an electrondonating $p-\pi$ conjugate effect. The conjugate effect plays a leading role and increases the electron cloud density on ortho- and para- positions, as a result, electrophilic substitution reaction can easily take place. However, as for BP2, the hydroxyl group is located next to a carbonyl group, and readily forms an intra-molecular hydrogen bond with the carbonyl group, which would decrease its reactivity. As for $\mathrm{BP} 12$, it has an extra octyloxy group on the 4-position compared to BP2, which would theoretically increase the reactivity due to its electron-donating effect. The low transformation ratio for BP12 resulted from the large steric hindrance effect. BP4 had no obvious toxicity change after chlorination treatment despite its $100 \%$ transformation ratio. Judging from the molecular structure of BP4, the hydroxyl group on the 4-position would increase its reactivity, and electrophilic chlorination readily occurred on the 3- and 5-positions. Generally, introducing chlorine atom into a molecule would increase its acute toxicity ( $\mathrm{Li}$ et al., 2011), while the unchanged toxicity of BP4 after chlorination treatment might be due to formation of some non-toxic small molecular products (Michalowicz et al., 2007). The transformation products and their toxicity should be studied in more detail. 


\subsection{Toxicity with significant decrease}

All BP compounds in Cluster 2 had significant toxicity decrease after chlorination disinfection, which means the products had less acute toxicity compared to their precursors, although most of them had high transformation ratios $(>80 \%)$. BP11 had an extra methoxyl group on the 4-position compared to BP2, and had a 59\% transformation ratio, while its toxicity significantly decreased after chlorination treatment, implying that the introduction of a methoxyl group would increase the reactivity while leading to products having lower toxicity than their precursor. BP14 had an extra hydroxyl group on the 2 'position compared to $\mathrm{BP} 11$, and the transformation ratio increased to $100 \%$, while its toxicity decreased after chlorination treatment. The introduction of a hydroxyl group on the 2 -position not only enhanced the reactivity but also increased the toxicity of BP14. However, the degree of toxicity decrease for BP14 after chlorination treatment was less significant than that of BP11. This result might be attributed to the products derived from BP14 having relatively higher toxicity than those derived from BP11.

Except for BP14 and BP11, the rest of the seven compounds in Cluster 2 contain only hydroxyl groups in their molecules. The number and position of these hydroxyl groups possibly determine their transformation ratios and toxicity changes. On one hand, the compounds with more hydroxyl groups exhibited much more significant toxicity decrease after chlorination treatment. For example, the ATFP of BP10 was quite a bit smaller than those of BP5 and BP6. The ATFP of BP7 was much smaller than those of BP2 and BP4. On the other hand, the position of hydroxyl groups had significant impact on their ATFPs. First, BPs with 2,4-di-hydoxylation (BP8, BP10, BP7 and BP9) or 3-hydroxylation (BP3) exhibited very significant toxicity decreases. In particular, BP9 (2,3,4-tri-hydroxyl-BP) had the smallest ATFP (0.04) among all the tested compounds. Considering the possible transformation mechanisms of BP-type UV filters in chlorination treatment, the diphenyl ketone would be oxidized to phenyl benzoate ester, which would be further hydrolyzed to benzoic acid and phenolic derivatives in the chlorination system (Negreira et al., 2008, 2012). Onodera and some other researchers have suspected that chlorinated acetic acid and maleic acids are formed from the destruction of the aromatic ring by chlorine in water (Onodera et al., 1984; Norwood et al., 1980). Michalowicz and coworkers detected carboxylic acids such as acetic and formic acid from the cleavage of phenolic aromatic rings, and the formation of non-toxic carboxylic acids decreased water toxicity (Michalowicz et al., 2007). In order to disclose the toxicity of these related compounds, benzophenone, phenyl benzoate ester, benzoic acid, and phenol were selected for more study. As shown in Fig. 4, the possible transformation products phenyl benzoate ester, benzoic acid and phenol had lower toxicity than their precursor benzophenone. This result

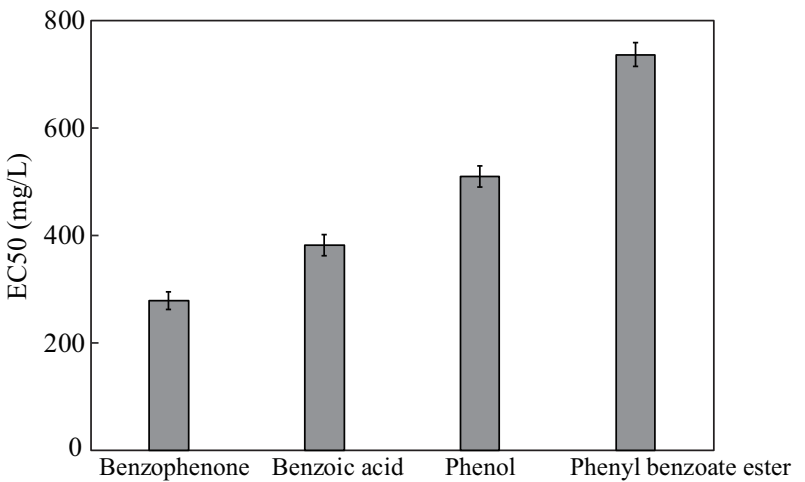

Fig. 4 EC50 values of benzophenone, benzoic acid, phenol and phenyl benzoate ester.

is in accordance with the toxicity decrease of BP-type UV filters after chlorination treatment to some extent. As for 2,4-di-hydroxylated BPs, the 3-, and 5-positions would be readily replaced by chlorine atoms, and for 3 hydroxylated BPs, the 2-, 4-, and 6-positions would easily be replaced by chlorine atoms. In general, aromatic rings with more substituents would be more readily broken into small molecules. Moreover, it was found that for those BP compounds with the same number of hydroxyl groups, the hydroxyl groups on one benzene ring had relatively small ATFP values after chlorination treatment compared to those with hydroxyl groups on two benzene rings. For instance, the ATFP value of BP7 was considerably lower than those of BP5 and BP6, and the ATFP value of BP9 was smaller than that of BP8. The possible reason may be attributed to the ready cleavage of aromatic rings with more hydroxyl groups. It has been demonstrated that chlorophenols and chlorinated quinines in pulp bleaching liquors were produced through oxidative cleavage of lignin side chains (4-substituted guaiacols and catechols) by aqueous chlorination (Larson and Rockwell, 1979; Lindstrom and Nordin, 1976).

\subsection{Toxicity with significant increase}

Among all studied BP compounds, only BP13 had a very significant toxicity increase after chlorination treatment. Considering the structural difference of BP13 compared to BP11, a sulfonic acid group was on 5-position of BP13, which would significantly increase the hydrophilicity and hinder the diffusion into cells. BP13 exhibited the minimum toxicity among all tested compounds. It seems that the sulfonic acid group is responsible for the toxicity elevation compared to that of BP11. However, except for desulfonation and electrophilic substitution reactions likely to occur in acidic or near neutral chlorination disinfection systems (Gilbert, 1965), it seems that the sulfonic acid group would not undergo any other reactions. Therefore, it is easy to understand that the EC50 of BP13 after chlorination treatment was still higher than that of BP11. 


\section{Environmental significance}

In order to simulate the acute toxicity formation potential of BP compounds in practical chlorination disinfection processes, an ambient water sample (dissolved organic carbon: $5.1 \mathrm{mg} / \mathrm{L}$; ammonia nitrogen: $0.2 \mathrm{mg} / \mathrm{L} ; \mathrm{pH} 8.2$ ) was collected from suburban Beijing, China. Three BPtype UV filters (BP4, BP7 and BP13) were selected to perform the chlorination treatment in the ambient water matrix. The experimental conditions and sample treatment procedures were as the same as the method described above. The EC50 values of the samples before and after chlorination treatment are shown in Fig. 5. Although only one ambient water sample was selected as matrix, the results had good accordance with chlorination treatments performed in the ultrapure water matrix. First, all 3 BPtype UV filters spiked in the ambient water matrix had almost $100 \%$ transformation ratios in the chlorination treatment, just as in the ultrapure water matrix. Second, after chlorination treatment in the ambient water matrix, the acute toxicity of BP4 had an insignificant change $(p>0.05)$, BP7 had a significant decrease $(p<0.001)$, while BP13 had a significant increase $(p<0.001)$, which were similar to those in the ultrapure water matrix. These results indicated that the transformation behaviors of BP-type UV filters could be replicated in a practical chlorination disinfection process. The acute toxicity formation potential (ATFP) could be used as an index to evaluate the possible fate and evaluate potential risk.

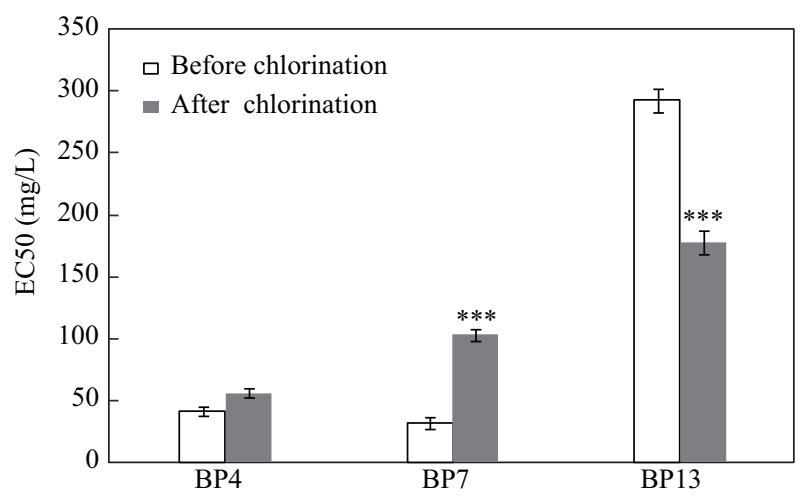

Fig. 5 EC50 values of three BPs (BP4, BP7 and BP13) before and after chlorination treatment in ambient water matrix. $* * * P<0.001$.

\section{Conclusions}

Acute toxicity of 14 BP-type UV filters before and after chlorination treatment was measured using a photobacterium bioassay. After chlorination disinfection treatment, the toxicity of 13 BP-type UV filters diminished more or less, while 2-hydroxy-4-methoxy benzophenone- 5-sulfonic acid had significant toxicity elevation. The toxicity changes could be attributed to the substitution effects and reactivity of the BPs. It was found that 2,4-dihydroxylated or 3-hydroxylated BPs exhibited significant toxicity decrease after chlorination treatment due to the ready cleavage of the aromatic ring. Importantly, the acute toxicity changes could be replicated in an ambient water matrix. This study could provide reference for scientifically evaluating the environmental fate and potential risk of BP-type UV filters in chlorination disinfection processes.

\section{Acknowledgments}

This work was supported by the National Natural Science Foundation of China (No. 21377143, 21077123 and 20877090).

\section{R E F E R E N C E S}

APHA (American Public Health Association), 1998. Standard Methods for the Examination of Water and Wastewater (20th ed.). Washington DC, USA.

Balmer, M.E., Buser, H.R., Mller, M.D., Poiger, T., 2005. Occurrence of some organic UV filters in wastewater, in surface waters, and in fish from Swiss Lakes. Envion. Sci. Technol. 39, 953-962.

EEC (European Economic Community), 1983. Council Directive 83/574/EEC of 26 october 1983 amending for the third time Directive 76/768/EEC on the approximation of the laws of the member states relating to cosmetic products. 332, 38-42.

Felix, T., Hall, B.J., Brodbelt, J.S., 1998. Determination of benzophenone-3 and metabolites in water and human urine by solid-phase microextraction and quadrupole ion trap GC-MS. Anal. Chim. Acta 371, 195-203.

Fluck, E.R., Poirier, L.A., Ruelius, H.W., 1976. Evaluation of a DNA polymerase-deficient mutant of $E$. coli for the rapid detection of carcinogens. Chem. Biol. Interact. 15, 219-231.

French, J.E., 1992. NTP technical report on toxicity studies of 2-hydroxy4-methoxy benzophenone (CAS No. 131-57-7) adminstered topically and in dosed feed to F344/N Rats and B6C3F1 Mice, Toxicity Report Series, 21, 1-E14.

Gilbert, E.E., 1965. Sulfonation and related reactions. Interscience Publishers, New York, pp. 1-529.

Hany, J., Nagel, R., 1995. Nachweis von UV-filter substanzen in muttermilch. Deutsche Lebensmittel-Rundschau, 91, 341-345.

Jeon, H.K., Chung, Y., Ryu, J.C., 2006. Simultaneous determination of benzophenone-type UV filters in water and soil by gas chromatography-mass spectrometry. J. Chromatogr. A 1131, 192202.

Jeon, H.K., Sarma, S.N., Kim, Y.J., Ryu, J.C., 2007. Forward gene mutation assay of seven benzophenone-type UV filters using L5178Y mouse lymphoma cell. Nat. Rev. Molec. Cell Biol. 3, 23-30.

Larson, R.A., Rockwell, A.L., 1979. Chloroform, and cyclophenol production by decarboxylation of natural acids during aqueous chlorination. Envion. Sci. Technol. 13, 325-329.

Li, W.H., Xu, X., 2001. Quantum chemical QSAR study on toxicities of chloranlines to photobacterium phosphoreum. J. South China Norm. Univ. 1, 76-78. 
Lindstrom, K., Nordin, J., 1976. Gas chromatography-mass spectrometry of chlorophenols in spent bleach liquors. J. Chromatogr. A 128, 13-26.

Ma, R., Cotton, B., Lichtensteiger, W., Schlumpf, M., 2003. UV Filters with antagonistic action at androgen receptors in the MDA-kb2 Cell transcriptional-activation assay. Toxicol. Sci. 74, 43-50.

MHLW (Ministry of Health and Welfare), 2000. Japanese standards of cosmetic ingredients. Ministry of Health and Welfare Notification. No. 331, Japan.

Michalowicz, J., Duda, W., Stufka-Olczyk, J., 2007. Transformation of phenol, catechol, guaiacol and syringol exposed to sodium hypochlorite. Chemosphere 66, 657-663.

Moloney, F.J., Collins, S., Murphy, G.M., 2002. Sunscreens: Safety, efficacy and appropriate use. Am. J. Clin. Dermatol. 3, 185-191.

Mortelmans, K., Haworth, S., Lawlor, T., Speck, W., Tainer, B., Zeiger, E., 1986. Salmonella mutagenicity tests: II. results from the testing of 270 chemicals. Environ. Mutagene. 8, 1-55.

NaÅecz-Jawecki, G., Rudź, B., Sawicki, J., 1997. Evaluation of toxicity of medical devices using Spirotox and Microtox tests: I. toxicity of selected toxicants in various diluents. J. Biomed. Mater. Res. 35, 101-105.

Negreira, N., Canosa, P., Rodrguez, I., Ramil, M., Rubí, E., Cela, R., 2008. Study of some UV filters stability in chlorinated water and identification of halogenated by-products by gas chromatographymass spectrometry. J. Chromatogr. A 1178, 206-214.

Negreira, N., Rodrguez, I., Rodil, R., Cela, R., 2012. Assessment of benzophenone-4 reactivity with free chlorine by liquid chromatography quadrupoe time-of-flight mass spectrometry. Anal. Chim. Acta 743, 101-110.

Norwood, D.L., Johnson, J.D., Christman, R.F., Hass, J.R., Bobenrieth, M. J., 1980. Reactions of chlorine with selected aromatic models of aquatic humic material. Envion. Sci. Technol. 14, 187-190.

Onodera, S., Udagawa, T., Tabata, M., Ishikura, S., Suzuki, S., 1984.
Isotachophoretic determination of chlorinated carboxylic acids formed during chlorination of phenol with hypochlorite in dilute aqueous solution. J. Chromatogr. A 287, 176-182.

Pan, Y.Q., Jiang, M.J., Lin, Y.Z., 2010. Research status of chlorination disinfection by-products in drinking water. Journal of China Resources Comprehensive Utilization 28, 31-34.

Rodil, R., Quintana, J. B., Lopez-Mahia, P., Muniategui-Lorenzo, S., Prada-Rodriguez, D., 2008. Multiclass determination of sunscreen chemicals in water samples by liquid chromatography-tandem mass spectrometry. Anal. Chem. 80, 1307-1315.

Schlumpf, M., Cotton, B., Conscience, M., Haller, V., Steinmann, B., Lichtensteiger, W., 2001. In vitro and in vivo estrogenicity of UV screens. Environ. Health Perspect. 109, 239-244.

Schreurs, R.H.M.M., Sonneveld, E., Jansen, J.H.J., Seinen, W., van der Burg, B., 2005. Interaction of polycyclic musks and UV filters with the estrogen receptor (ER), androgen receptor (AR), and progesterone receptor (PR) in reporter gene bioassays. Toxicol. Sci. 83, 264-272.

Suzuki, T., Kitamura, S., Khota, R., Sugihara, K., Fujimoto, N., Ohta, S., 2005. Estrogenic and antiandrogenic activities of 17 benzophenone derivatives used as UV stabilizers and sunscreens. Toxicol. Appl. Pharmacol. 203, 9-17.

Ye, Z.F., Zhao, Q.L., Zhang, M.H., Gao, Y.C., 2011. Acute toxicity evaluation of explosive wastewater by bacterial bioluminescence assays using a freshwater luminescent bacterium, Vibrio qinghaiensis sp. Nov. J. Hazard. Mater. 186, 1351-1354.

Zeiger, E., Anderson, B., Haworth, S., Lawlor, T., Mortelmans, K., Speck, W., 1987. Salmonella mutagenicity tests: III. Results from the testing of 255 chemicals. Environ. Mutagen. 9, 61-109.

Zenker, A., Schmutz, H., Fent, K.J., 2008. Simultaneous trace determination of nine organic UV-absorbing compounds (UV filters) in environmental samples. J. Chromatogr. A 1202, 64-74. 